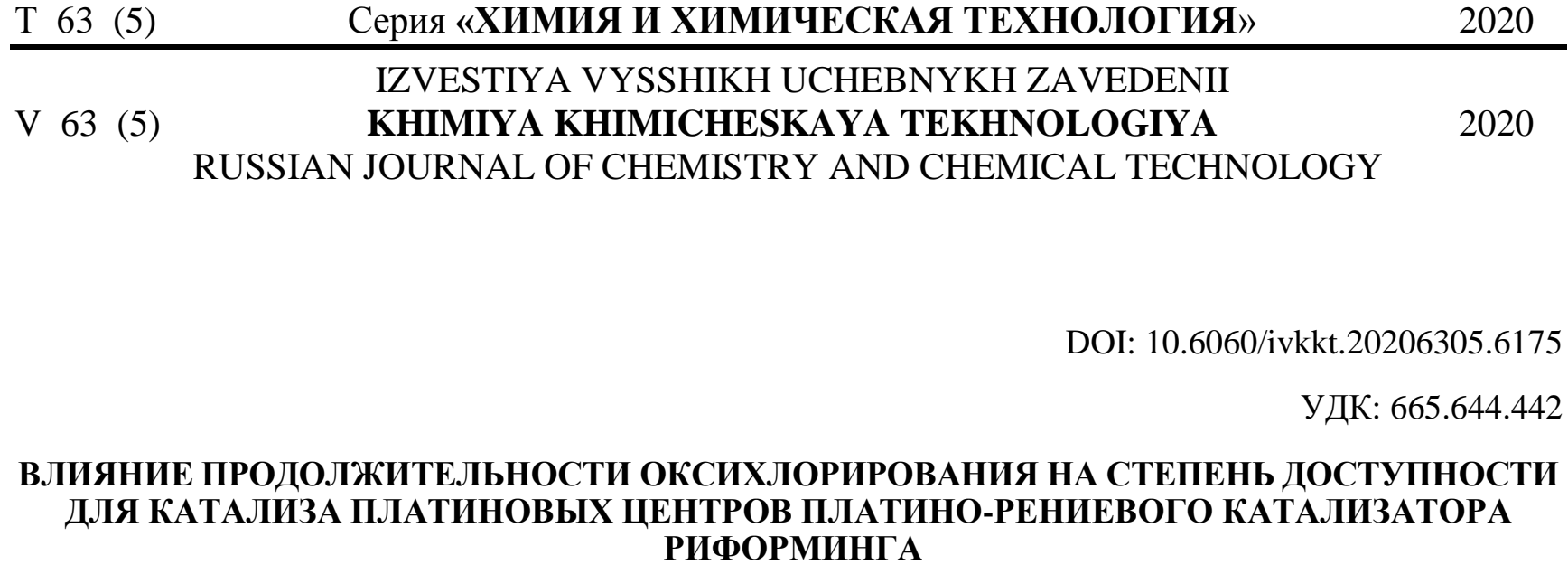

ИЗВЕСТИЯ ВЫСШИХ УЧЕБНЫХ ЗАВЕДЕНИЙ. РИФОРМИНГА

\author{
А.Г. Старостин, Н.Б. Ходяшев
}

Андрей Георгиевич Старостин *

Кафедра Химические технологии, Пермского национального исследовательского политехнического университета, Комсомольский просп., 29, Пермь, Российская Федерация, 614990

E-mail: starostin26@yandex.ru *

Николай Борисович Ходяшев

Кафедра Химия и Биотехнология, Пермского национального исследовательского политехнического университета, Комсомольский просп., 29, Пермь, Российская Федерация, 614990

E-mail: vvv@pstu.ru

В работе приведены результаты хемосорбционного анализа платино-рениевого катализатора на носителе из оксида алюминия после регенерации и восстановления водородом. Путем проведения ступенчатой импульсной хемосорбции окиси углерода на образцах катализатора риформинга получены диаграммы адсорбции-десорбции, при этом с увеличением количества инжсекций окиси углерода с 1 до 4 происходит отравление образца катализатора, а последующие пики десорбции свидетельствуют о прекращении взаимодействия. С увеличением времени оксихлорирования происходит рост отночения СО/Pt в объеме носителя по линейному закону. Показано влияние процесса оксихлорирования на хемосорбцию СО и последующую доступность для катализа наночастиц платины. Поглощение на свежеприготовленных образцах платино-рениевого катализатора достигает значений мольного отнощения СО/Pt, равного примерно 0,4. Полученные результаты показывают, что продолжительность оксихлорирования в течение 16-20 ч позволяет достичь величины отношения СО/Pt, находящейся в пределах 0,4-0,5. Это свидетельствует о том, что доступность платиновых центров в его составе выходит на уровень свежего катализатора, а с другой стороны, принимая во внимание некоторое превышение этого соотношения, можно предположить, что и часть атомов Re участвует в процессе поглощения молекул СО. Методом ИК-спектроскопии подтверждено наличие высокодисперсных частиц платины в составе регенерированного катализатора. Проведенный анализ образцов катализатора на ИК-спектрометре в области частот 1900-2200 см-1 позволил выявить достаточно широкую полосу поглощения с выраженным экстремумом при $2060 \mathrm{~cm}^{-1}$. В этой области частот имеется другой, слабовыраженный экстремум при 2149 см. $^{-1}$. Однако для образцов с малой продолжительностью оксихлорирования он не проявлялся. Полоса погло-

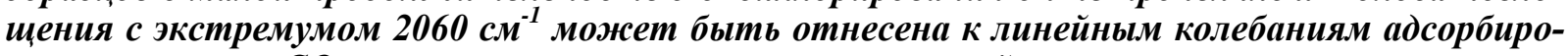
ванных молекул СО на поверхности частиц металлической платины.

Ключевые слова: каталитический риформинг, платино-рениевый катализатор, оксихлорирование, хемосорбция СО, доступность Pt-центров 


\title{
EFFECT OF DURATION OF OXYCHLORINATION ON DEGREE OF ACCESSIBILITY FOR CATALYSIS OF PLATINUM CENTERS OF PLATINUM-RHENIUM REFORMING CATALYST
}

\author{
A.G. Starostin, N.B. Khodyashev
}

Andrey G. Starostin *

Department of Chemical Technology, Perm National Research Polytechnic University, Komsomolsky ave., 29, Perm, 614990, Russia

E-mail: starostin26@yandex.ru *

Nikolai B. Khodyashev

Department of Chemistry and Biotechnology, Perm National Research Polytechnic University, Komsomolsky ave., 29, Perm, 614990, Russia

E-mail:vvv@pstu.ru

The work presents the results of a chemisorption analysis of a platinum-rhenium catalyst on an alumina support after regeneration and reduction with hydrogen. Adsorption-desorption diagrams were obtained by stepwise-pulsed chemisorption of carbon monoxide on reforming catalyst samples. With an increase in the number of carbon monoxide injections from 1 to 4, the catalyst sample is poisoned, and subsequent desorption peaks indicate the termination of the interaction. With an increase in the time of oxychlorination, the CO/Pt ratio in the carrier volume increases linearly. The effect of the oxychlorination process on the chemisorption of $C O$ and the subsequent availability of platinum nanoparticles for catalysis has been shown. The absorption on freshly prepared platinum-rhenium catalyst samples reaches a CO/Pt molar ratio of about 0.4 . The results show that the duration of oxychlorination for 16-20 h allows us to achieve the value of the ratio CO/Pt, which is in the range of 0.4-0.5. This indicates that the availability of platinum centers in its composition reaches the level of a fresh catalyst, and, on the other hand, taking into account a slight excess of this ratio, we can assume that some of the Re atoms participate in the absorption of $\mathrm{CO}$ molecules. The presence of finely dispersed platinum particles in the composition of the regenerated catalyst was confirmed by IR spectroscopy. The analysis of catalyst samples on an IR spectrometer in the frequency range of $1900-2200 \mathrm{~cm}^{-1}$ revealed a rather wide absorption band with a pronounced extremum at $2060 \mathrm{~cm}^{-1}$. In this frequency range, there is another, slightly pronounced extremum at $2149 \mathrm{~cm}^{-1}$. However, for samples with a short duration of oxychlorination, it did not appear. An absorption band with an extremum of $2060 \mathrm{~cm}^{-1}$ can be attributed to linear vibrations of adsorbed $\mathrm{CO}$ molecules on the surface of particles of metallic platinum.

Key words: catalytic reforming, platinum-rhenium catalyst, oxychlorination, $\mathrm{CO}$ chemisorption, $\mathrm{Pt}$ centers availability

Для цитирования:

Старостин А.Г., Ходяшев Н.Б. Влияние продолжительности оксихлорирования на степень доступности для катализа платиновых центров платино-рениевого катализатора риформинга. Изв. вузов. Химия и хим. технология. 2020. Т. 63. Вып. 5. С. 59-64

For citation:

Starostin A.G., Khodyashev N.B. Effect of duration of oxychlorination on degree of accessibilityfor catalysis of platinum centers of platinum-rhenium reforming catalyst. Izv. Vyssh. Uchebn. Zaved. Khim. Khim. Tekhnol. [Russ. J. Chem. \& Chem. Tech.]. 2020. V. 63. N 5. P. 59-64

ВВЕДЕНИЕ

Платина является одним из наиболее эффективных компонентов катализаторов риформинга в технологии высокооктановых бензинов, топливных элементах, катализаторах дожига выхлопных газов автомобилей и др. [1-3]. В технологическом цикле риформинга широко используют катализаторы различных марок на носителе 
$\gamma-\mathrm{Al}_{2} \mathrm{O}_{3}$ с массовым содержанием платины менее 1 мас.\%, высокой степенью дисперсности и добавками других металлов [3]. Причем, судя по литературным сведениям, наибольшее распространение получили платино-рениевые катализаторы как зарубежных, так и отечественных производителей [3-10]. Введение наряду с платиной рения приводит к увеличению активности и стабильности работы катализаторов [3, 5].

Однако, при эксплуатации катализаторов происходит их закоксовывание, агрегация нанодисперсных частиц платины, что в значительной степени снижает выпуск готовой продукции и приводит к низкой эффективности использования дорогостоящей платины. Снижение активности катализаторов риформинга в реакционном периоде обусловлено, главным образом, коксоотложением. В то же время, на стадии окислительной регенерации оно связано со спеканием платины [8, 11-16].

Методы редиспергирования платины в составе катализаторов риформинга хорошо известны и широко используются в нефтехимических производствах. Они заключаются в окислении поверхностных атомов кристаллитов платины в присутствии кислорода и ионов хлора с образованием оксихлоридов платины. Последние являются подвижными и легко мигрируют по поверхности катализатора [3]. Последующее восстановление водородом приводит к образованию высокодисперсных частиц платины.

Необходимо отметить, что в ходе продолжительной эксплуатации катализаторов риформинга на их поверхности происходит накопление примесей, что может оказывать влияние на процесс оксихлорирования и в целом на стадию редиспергирования платины. В свою очередь, дисперсность платиновых центров катализатора будет связана с временными характеристиками стадии оксихлорирования. Указанное явилось одной из задач исследования настоящей работы.

\section{МЕТОДИКА ЭКСПЕРИМЕНТА}

Для проведения исследования использованы промышленные образцы платино-рениевого катализатора риформинга ООО "ЛУКОЙЛПермнефтеоргсинтез", прошедшие стадию выжига кокса и последующего оксихлорирования с различной продолжительностью парогазовоздушной смесью, содержащей $\mathrm{H}_{2} \mathrm{O}, \mathrm{O}_{2}$ и хлорорганический компонент - трихлорэтилен. Катализатор на основе $\gamma-\mathrm{Al}_{2} \mathrm{O}_{3}$ имел следующие характеристики: содержание Pt-0,25 мас.\%, Re-0,4 мас.\%; частицы цилиндрической формы диаметром 1,6 мм, удельная поверхность $-180 \mathrm{~m}^{2} / \Gamma$, насыпная плотность

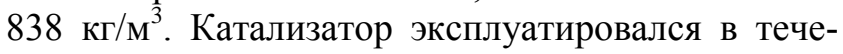
ние длительного времени, выдержал 12 межрегенерационных пробегов. Отбор проб катализатора на стадии оксихлорирования проведен непосредственно на промышленной установке через определенные промежутки времени.

Восстановление образцов платинорениевого катализатора проведено водородом на лабораторной установке в следующих условиях: температура $-480{ }^{\circ} \mathrm{C}$, продолжительность -2 ч,

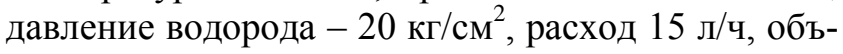
ем образца катализатора - 10 мл.

Доля активных поверхностных атомов платины определена путем хемосорбции СО при комнатной температуре. Для этой цели использовали восстановленные водородом образцы платино-рениевого катализатора. Инжекцию СО осуществляли объемом 0,1 мл (99,99 мас.\%) до момента полного отравления образцов катализатора. Принцип анализа заключался в определении кумулятивного эффекта отравления катализатора окисью углерода, при котором прекращается поглощение сорбируемого газа образцом.

Объем хемосорбированного газа был рассчитан с применением программного обеспечения прибора Micromeritics «ChemiSorb 2720» путем корреляции площади подинтегральной кривой диаграммы адсорбции/десорбции по формуле:

$$
V_{\text {aдc }}=\frac{V_{\text {unp }}}{M} \cdot \sum_{i=1}^{n}\left(1-\frac{A_{i}}{A_{f}}\right),
$$

где: $V_{\text {unр }}$ - впрыснутый объем шприца, приведенный к нормальным условиям, см $^{3} ; M$ - масса образца, г; $A_{i}-$ площадь і-го пика; $A_{f}-$ площадь последнего пика.

Мольное отношение $A$, моль $\mathrm{CO}$ ммоль $\mathrm{Pt}$ определяли исходя из объема хемосорбированного газа по формуле:

$$
A=\frac{V_{a \partial c}}{V_{c m \partial}} \cdot \frac{\mathcal{M . M .} .}{\% M} \cdot 100 \%,
$$

где: $V_{\text {адс }}-$ адсорбированный объем, см$^{3} ; V_{c m д}-$ молярный объем газа при стандартных условиях, $\mathrm{cm}^{3} ;$ м.м. - молекулярная масса платины, а.е.м.; $\% M$ - содержание платины в составе образца, мас. \%.

Образцы после хемосорбции СО использовали для ИК-спектроскопического анализа. Для проведения анализа применяли ИК-Фурьеспектрометр Nicollet-380 с приставкой для диффузного отражения. Пробоподготовка осуществлялась по стандартной методике с минимальным контактом образцов с атмосферой воздуха. 


\section{РЕЗУЛЬТАТЫ И ИХ ОБСУЖДЕНИЕ}

Путем проведения ступенчатой импульсной хемосорбции окиси углерода на образцах катализатора риформинга получены диаграммы адсорбции-десорбции. На представленной диаграмме (рис. 1) можно видеть, как с увеличением количества инжекций окиси углерода с 1 до 4 происходит отравление образца катализатора, а последующие пики десорбции свидетельствуют о прекращении взаимодействия (при этом интенсивность пиков с 5 по 8 практически одинакова).

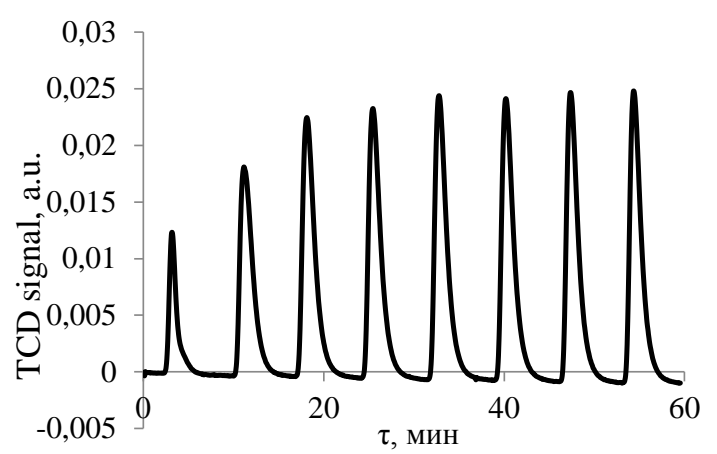

Рис. 1. Ступенчатая импульсная хемосорбция оксида углерода (II) образцом катализатора с продолжительностью оксихлорирования в течение 16 ч

Fig.1. Stepwise pulsed chemisorption of carbon monoxide (II) by a catalyst sample with a duration of oxychlorination for $16 \mathrm{~h}$

Результаты анализа хемосорбции окиси углерода на платино-рениевом катализаторе после проведения процесса оксихлорирования в течение 4-20 ч приведены на рис. 2. Как следует из рисунка, с увеличением времени оксихлорирования происходит рост отношения $\mathrm{CO} / \mathrm{Pt}$ (обозн. n) в объеме носителя по линейному закону. При этом коэффициент корреляции для полученной зависимости равен 0,98 .

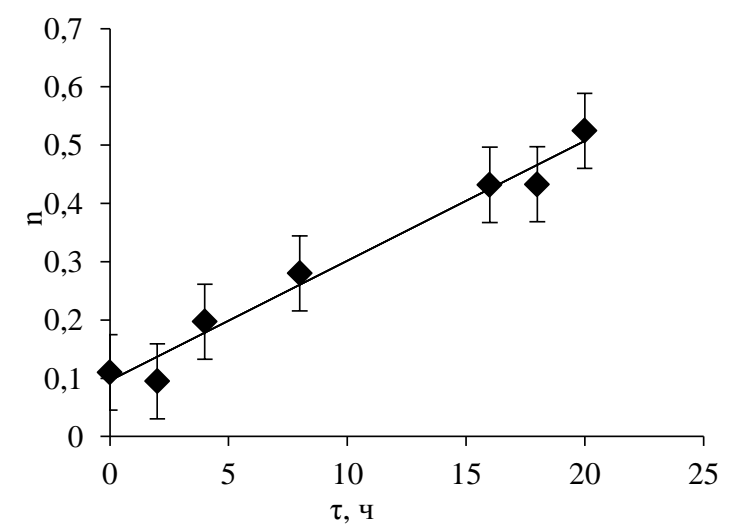

Рис. 2. Мольное отношение $\mathrm{CO} / \mathrm{Pt}=\mathrm{n}$ в составе платино-рениевого катализатора после оксихлорирования с различной продолжительностью и последующего восстановления водородом Fig. 2. The molar ratio of $\mathrm{CO} / \mathrm{Pt}=\mathrm{n}$ in the composition of the platinum-rhenium catalyst after oxychlorination with various durations and subsequent reduction with hydrogen
Учитывая литературные сведения [17], поглощение на свежеприготовленных образцах платино-рениевого катализатора достигает значений мольного отношения $\mathrm{CO} / \mathrm{Pt}$, равного примерно 0,4. Исходя из этого, можно отметить следующее. Экспериментальные результаты (рис. 2) показывают, что время оксихлорирования 16-20 ч дает величины отношения $\mathrm{CO} / \mathrm{Pt}$, находящиеся в пределах 0,4-0,5. Это свидетельствует о том, что доступность платиновых центров в составе катализатора выходит на уровень свежего катализатора, а с другой стороны, принимая во внимание некоторое превышение этого соотношения, можно предположить, что и часть атомов Re участвует в процессе поглощения молекул СО. Литературные сведения указывают на возможность существования соединения $\operatorname{Re}_{2}(\mathrm{CO})_{10}$ [18].

$\mathrm{C}$ целью более глубокого изучения адсорбции молекул СО на поверхности платинорениевого катализатора выполнен ИК-спектроскопический анализ образцов. В качестве примера на рис. 3 представлен ИК спектр образца катализатоpa c максимальной продолжительностью оксихлорирования после хемосорбции СО в сопоставлении с контрольным образцом (сорбция СО не проводилась).

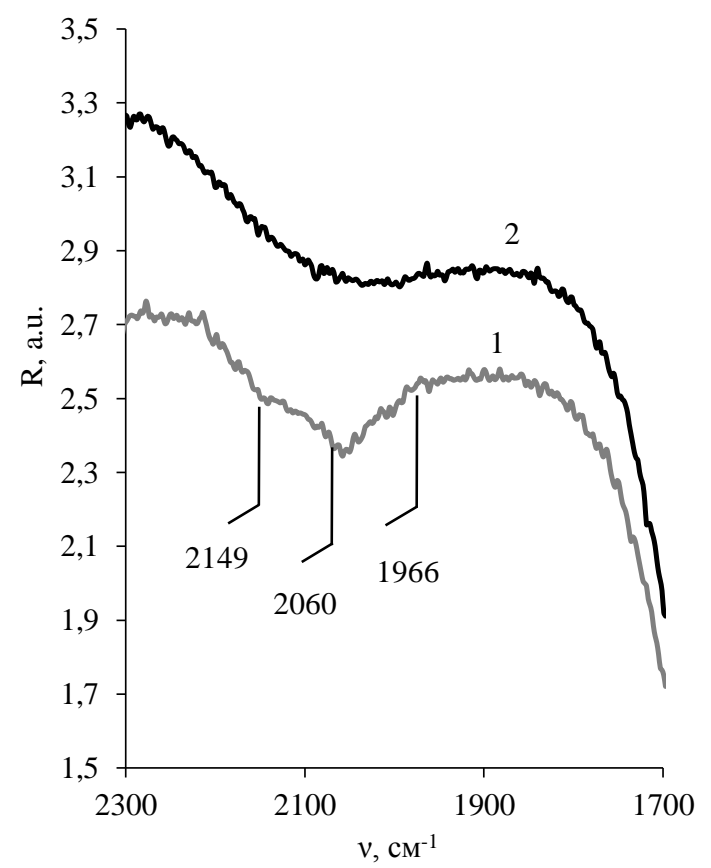

Рис. 3. ИК спектры восстановленного водородом платинорениевого катализатора с продолжительностью оксихлорирования 20 ч. 1 - после хемосорбции оксида углерода (II); 2 контрольный образец (без поглощения оксида углерода (II)) Fig. 3. IR spectra of hydrogen-reduced platinum-rhenium catalyst with a duration of oxychlorination of $20 \mathrm{~h} .1$ - after chemisorption of carbon monoxide (II); 2 - control sample (without absorption of carbon monoxide (II)) 
Анализ в области частот 1900-2200 $\mathrm{cm}^{-1}$ позволяет выявить достаточно широкую полосу поглощения с выраженным экстремумом при $2060 \mathrm{~cm}^{-1}$. В этой области частот имеется другой, слабовыраженный экстремум при $2149 \mathrm{~cm}^{-1}$. Однако для образцов с меньшей продолжительностью оксихлорирования он не проявляется. Как следует из литературных сведений $[17,18]$, полоса поглощения с экстремумом $2060 \mathrm{~cm}^{-1}$ может быть отнесена к линейным колебаниям адсорбированных молекул СО на поверхности частиц металлической платины. Положение ее экстремума может изменяться в определенных пределах в зависимости от дисперсности частиц платины. Причем, как показано в публикациях [19-23], с ростом дисперсности платины смещение экстремума происходит в сторону меньших частот и достигает положения 2060-2050 $\mathrm{cm}^{-1}$, что достаточно близко к полученным данным для рассматриваемого платинорениевого катализатора. Относительно низкая интенсивность рассматриваемой полосы поглощения

\section{Л И Т Е Р А Т У Р А}

1. Чоркендорф И., Наймантсведрайт Х. Современный катализ и химическая кинетика. Долгопрудный: ИД «Интеллект». 2010. 504c.

2. Бельская О.Б., Гуляева Т.И. Роль гидролизованных форм предшественника в формировании адсорбционных и каталитических свойств нанесенной платины в катализаторах $\mathrm{Pt} / \mathrm{Al}_{2} \mathrm{O}_{3}$. Катализ в пром-ти. 2013. №6. C. 9-20.

3. Autos G.J., Aitani A.M., Parera J.M. Catalytic Nafta Reforming. Science and Technology. NY: Marcel Dekker Inc. $1995.516 \mathrm{p}$.

4. Кирьянов Д.И. Современное состояние процесса каталитического риформинга бензиновых фракций. Опыт производства и промышленной эксплуатации катализаторов риформинга серии ПР. Рос. хим. журн. 2007. T. LI. № 4. C. 60-68.

5. Белый А.С. Современные представления о состоянии платины в нанесенных катализаторах для производства моторных топлив. Рос. хим. журн. 2007. T. LI. № 4. C. 38-47.

6. Белый А.С. Научные основы приготовления и усовершенствования технологии производства катализаторов риформинга серии ПР. Кинетика и катализ. 2005. Т. 46. № 5. С. 728-736.

7. Белый А.С. Дизайн катализаторов риформинга. Создание новых технологий производства моторных топлив на их основе. Кинетика и катализ. 2008. Т. 49. № 4. C. $587-591$.

8. Шарова Е.С. Мониторинг промышленной эксплуатации катализаторов риформинга с использованием компьютерной моделирующей системы. Катализ в промти. 2009. №3. С. 29-34.

9. Крачилов Д.К., Тишкина О.Б., Елшин А.И. Анализ показателей работы российских и зарубежных катализаторов риформинга на отечественных нефтеперерабатывающих заводах. Нефтеперераб. и нефтехим. 2012. № 3. C. 3-11. объясняется низкой концентрацией платины в целом в составе катализатора.

\section{ВЫВОДЫ}

Таким образом, выполненное исследование показало, что платино-рениевый катализатор риформинга, прошедший многоцикловую эксплуатацию, в ходе регенерации и последующего оксихлорирования восстанавливает доступность платиновых центров на уровне свежего катализатора. Результаты ИК-спектроскопического анализа подтвердили наличие высокодисперсной металлической платины в составе каталитических центров.

Работа выполнена с использованием научного оборудования центров «Технологий сорбентов и катализаторов» $и$ «Наукоемких химических технологий и физико-химических исследований» Пермского национального исследовательского политехнического университета.

\section{REFERENCES}

1. Chorkendorf I., Naimantsvedwright X. Modern Catalysis and Chemical Kinetics. GmbH: Wiley-VCH Verlag. 2007. $504 \mathrm{p}$.

2. Belskaya O.B., Gulyaeva T.I. The role of hydrolyzed forms of the precursor in the formation of the adsorption and catalytic properties of supported platinum in $\mathrm{Pt} / \mathrm{Al}_{2} \mathrm{O}_{3}$ catalysts. Katal. Prom. 2013. N 6. P. 9-20 (in Russian).

3. Autos G.J., Aitani A.M., Parera J.M. Catalytic Nafta Reforming. Science and Technology. NY: Marcel Dekker Inc. $1995.516 \mathrm{p}$

4. Kiryanov D.I. Modern state of the catalytic reforming of petrol fractions. Experience of manufacture and industrial exploitation of reforming catalysts of the PR series. Russ. J. Gen. Chem. 2007. V. 77. N 12. P. 2255-2264.

5. Belyi A.S. Modern views on the state of platinum in supported catalysts for production of motor fuels. Russ. J. Gen. Chem. 2007. V. 77. N 12. C. 2243-2254.

6. Belyi A.S. Reforming catalysts of the PR family: Scientific foundations and technological advancement. Kinet. Catal. 2005. V. 46. N. 5. P. 684-692.

7. Belyi A.S. Design of reforming catalysts: Development of new technologies for the manufacture of motor fuels on this basis. Kinet. Catal. 2008. V. 49. N. 4. P. 562-567.

8. Sharova E.S., Poluboyartsev D.S., Chekantsev N.V. Monitoring of the commercial operation of reforming catalysts using a computer simulation system. Catal. Indust. 2009. V. 1. N 2. P. 128-133.

9. Krachilov D.K., Tishkina O.B., Elshin A.I. Analysis of performance indicators of Russian and foreign reforming catalysts at domestic oil refineries. Neftepererab. Neftekhim. 2012. N 3. P. 3-11 (in Russian).

10. Pleshakova N.A., Rohmanko E.N., Salmina I.V. The experience of operating domestic and foreign reforming catalysts on various types of raw materials. Neftepererab. Neftekhim. 2013. N 6. P. 21-25 (in Russian). 
10. Плешакова Н.А., Рохманько Е.Н., Салмина И.В. Опыт эксплуатации отечественных и зарубежных катализаторов риформинга на различных типах сырья. Нефтеперераб. и нефтехим. 2013. № 6. С. 21-25

11. Костенко А.В., Молотов К.В., Кравцов А.В. Мониторинг установки ЛЧ-35-11/1000 с использованием компьютерной системы контроля работы катализаторов риформинга. Нефтеперераб. и нефтехим. 2007. № 4. C. 13-16.

12. Костенко А.В., Молотов А.В., Иванчина Э.Д. Разработка и применение технологических критериев оценки активности и стабильности Pt-катализаторов риформинга бензинов методом математического моделирования Нефтеперераб. и нефтехим. 2007. № 6. С. 18-22.

13. Кравцов А.В., Иванчина Э.Д., Костенко А.В. Анализ эффективности эксплуатации платиносодержащих катализаторов процесса риформинга бензинов с использованием компьютерной моделирующей системы. Нефтеперераб. и нефтехим. 2008. № 11. С. 18-23.

14. Шарова Е.С., Фадеев С.А., Иванчина Э.Д. Исследование состава и свойств Pt-катализаторов промышленного процесса риформинга. Изв. Томск. политехн. унma. 2012. T. 320. № 3. С. 89-92.

15. Крылов В.А., Ходяшев Н.Б., Подвинцев И.Б. Влияние характера коксовых отложений на показатели работы платино - рениевого катализатора риформинга. Нефтеперераб. и нефтехим. 2013. № 5. С. 14-18.

16. Аликин А.Г., Ускова Е.С., Ходяшев Н.Б. Применение методов термического анализа для оценки эффективности работы платино-рениевого катализатора риформинга. Нефтеперераб. и нефтехим. 2016. № 11. С.13-17.

17. Pieck C.L. Metal dispersion and catalytic activity of trimetallic Pt-Re-Sn/ $\mathrm{Al}_{2} \mathrm{O}_{3}$ naphta reforming catalysts. Catal. Today. 2005. V. 107-108. P. 637-742.

18. Anderson J.A., Chong F.K., Rochester C.H. IR study of $\mathrm{CO}$ adsorption on $\mathrm{Pt}, \mathrm{Re}$ and $\mathrm{Pt}-\mathrm{Re} / \mathrm{Al}_{2} \mathrm{O}_{3}$ catalysts before and after coking. J. Mol. Catal. A: Chem. 1999. V. 140. N 1. P. 65-80.

19. Allian A.D. Chemisorption of $\mathrm{CO}$ and mechanism of $\mathrm{CO}$ oxidation on supported platinum nanoclusters. J. Am. Chem. Soc. J. Am. Chem. Soc. 2011. V. 133. N 12. P. 4498-4517. DOI: $10.1021 /$ ja110073u.

20. Lentz C., Jand S.P., Melke J. Drifts study of CO adsorption on Pt nanoparticles supported by DFT calculations. $J$. Mol. Catal. A: Chem. 2017. V. 426. P. 1-9.

21. Panahi M., Solati N., Gurlek S. Weakening the strength of CO binding on subsurface alloyed Pt(III). Surf. Sci. 2019. V. 682. P. 1-7.

22. Lachkov P.T, Chin Y-H.C. Catalytic consequences of reactive intermediates during co oxidation on Ag clusters. ACS Catal. 2018. V. 8. P. 11987-11998. DOI: 10.1021 /acscatal.8b01760.

23. Yourdshahyan Y., Cooper V.R., Kolpak A.M., Rappe A.M. Catalytic behavior at the nanoscale: $\mathrm{CO}$ adsorption on $\mathrm{Al}_{2} \mathrm{O}_{3}$-supported Pt clusters. Proc. SPIE 5223, Physical Chemistry of Interfaces and Nanomaterials II. Bellingham. 2003. P. 223-231. DOI: 10.1117/12.508615.
11. Kostenko A.V., Molotov K.V., Kravtsov A.V. Monitoring of the LCH-35-11/1000 installation using a computer system for monitoring the operation of reforming catalysts. Neftepererab. Neftekhim. 2007. N 4. P. 13-16 (in Russian).

12. Kostenko A.V., Molotov A.V., Ivanchina E.D. Development and application of technological criteria for assessing the activity and stability of Pt-catalysts for gasoline reforming by mathematical modeling. Neftepererab. Neftekhim. 2007. N 6. P. 18-22 (in Russian).

13. Kravtsov A.V., Ivanchina E.D., Kostenko A.V. Analysis of the operational efficiency of platinum-containing catalysts for gasoline reforming using a computer modeling system. Neftepererab. Neftekhim. 2008. N 11. P. 18-23 (in Russian).

14. Sharova E.S., Fadeev S.A., Ivanchina E.D. Study of the composition and properties of Pt catalysts of the industrial reforming process. Izv. Tomsk. Polytekh. Univ. 2012. V. 320. N. 3. P. 89-92 (in Russian).

15. Krylov V.A., Khodyashev N.B., Podvintsev I.B. The influence of the nature of coke deposits on the performance of the platinum-rhenium reforming catalyst. Neftepererab. Neftekhim. 2013. N 5. P. 14-18 (in Russian).

16. Alikin A.G., Uskova E.S., Khodyashev N.B. The use of thermal analysis methods to assess the performance of the platinum-rhenium reforming catalyst. Neftepererab. Neftekhim. 2016. N 11. P. 13-17 (in Russian).

17. Pieck C.L. Metal dispersion and catalytic activity of trimetallic Pt-Re-Sn $/ \mathrm{Al}_{2} \mathrm{O}_{3}$ naphta reforming catalysts. Catal. Today. 2005. V. 107-108. P. 637-742.

18. Anderson J.A., Chong F.K., Rochester C.H. IR study of $\mathrm{CO}$ adsorption on $\mathrm{Pt}, \mathrm{Re}$ and $\mathrm{Pt}-\mathrm{Re} / \mathrm{Al}_{2} \mathrm{O}_{3}$ catalysts before and after coking. J. Mol. Catal. A: Chem. 1999. V. 140. N 1. P. 65-80.

19. Allian A.D. Chemisorption of $\mathrm{CO}$ and mechanism of $\mathrm{CO}$ oxidation on supported platinum nanoclusters. J. Am. Chem. Soc. 2011. V. 133. N 12. P. 4498-4517. DOI: 10.1021/ja110073u.

20. Lentz C., Jand S.P., Melke J. Drifts study of CO adsorption on Pt nanoparticles supported by DFT calculations. $J$. Mol. Catal. A: Chem. 2017. V. 426. P. 1-9.

21. Panahi M., Solati N., Gurlek S. Weakening the strength of CO binding on subsurface alloyed Pt(III). Surf. Sci. 2019. V. 682. P. 1-7.

22. Lachkov P.T, Chin Y-H.C. consequences of reactive intermediates during co oxidation on Ag clusters. ACS Catal. 2018. V. 8. P. 11987-11998. DOI: 10.1021/acscatal.8b01760.

23. Yourdshahyan Y., Cooper V.R., Kolpak A.M., Rappe A.M. Catalytic behavior at the nanoscale: $\mathrm{CO}$ adsorption on $\mathrm{Al}_{2} \mathrm{O}_{3}$-supported Pt clusters. Proc. SPIE 5223, Physical Chemistry of Interfaces and Nanomaterials II. Bellingham. 2003. P. 223-231. DOI: 10.1117/12.508615.

Поступила в редакиџюю 05.12.2019

Принята к опубликованию 10.03.2020

Received 05.12.2019

Accepted 10.03.2020 